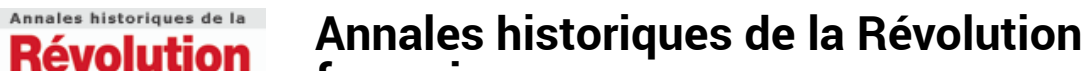

française française

378 | octobre-décembre 2014

Varia

\section{Brice MARTINETTI, Les Négociants de La Rochelle au} XVIII siècle

Préface de Didier POTON, Rennes, Presses universitaires de Rennes, 2013

\section{Sylvain Turc}

\section{(2) OpenEdition \\ 1 Journals}

\section{Édition électronique}

URL : https://journals.openedition.org/ahrf/13400

DOI : $10.4000 /$ ahrf. 13400

ISSN : 1952-403X

Éditeur :

Armand Colin, Société des études robespierristes

\section{Édition imprimée}

Date de publication : 1 décembre 2014

Pagination : 174-177

ISBN : 978-2-200-92928-2

ISSN : 0003-4436

Référence électronique

Sylvain Turc, "Brice martinetTI, Les Négociants de La Rochelle au XVIIIe siècle ", Annales historiques de la Révolution française [En ligne], 378 | octobre-décembre 2014, mis en ligne le 01 décembre 2014,

consulté le 01 juillet 2021. URL : http://journals.openedition.org/ahrf/13400 ; DOI : https://doi.org/ 10.4000/ahrf. 13400

Ce document a été généré automatiquement le 1 juillet 2021.

Tous droits réservés 


\section{Brice MARTINETTI, Les Négociants de La Rochelle au XVIII ${ }^{e}$ siècle}

Préface de Didier PотоN, Rennes, Presses universitaires de Rennes, 2013

\section{Sylvain Turc}

\section{RÉFÉRENCE}

Brice MARTINETTI, Les Négociants de La Rochelle au XVIII ${ }^{e}$ siècle, préface de Didier POTON, Rennes, Presses universitaires de Rennes, 2013, 447 p., ISBN 978-2-7535-2853-6, $24 €$.

1 Jadis fer de lance de la recherche historique française dans les années 1960 et 1970, l'histoire économique et sociale avait perdu de son attrait lors de l'émergence de l'histoire culturelle et le renouveau de l'histoire politique. Fort heureusement, des travaux novateurs, dont ceux de Patrick Verley, ont redonné vie à l'analyse des circulations en montrant que ces phénomènes se plaçaient au fondement de la croissance observée en Europe à partir du XVIII ${ }^{\mathrm{e}}$ siècle.

2 Prenant acte du changement de focale, Brice Martinetti nous offre une belle étude sur le grand commerce rochelais et ses acteurs lors du dernier siècle de l'époque moderne. Pas à pas, il décrit un "écosystème négociant" - entendons une structure socioéconomique - triomphant vers 1760, mais rapidement " obsolète » (pP.18) sous l'effet des révoltes insulaires et de l'interdiction de la traite - soit l'apogée et le déclin d'un cycle colonial. Dans le sillage des travaux de Philippe Gardey trop ignorés (Négociants et marchands de Bordeaux. De la guerre d'Amérique à la Restauration (1780-1830), paru aux PUPS en 2009), dont les analyses constituent l'arrière-fond permanent de l'ouvrage, l'auteur se veut l'historien des acteurs bien plus que des trafics, mais il sait relier les destins des hommes aux dynamiques commerciales. En procédant de la sorte, il renoue les liens avec l'historiographie du négoce des villes portuaires qu'ont illustrée Pierre Dardel, Paul Butel, Charles Carrière, et, plus récemment, André Lespagnol, Olivier PétréGrenouilleau et Pierre Jeannin, mais les recherches en partie inédite de K. Audran et Laure Pineau-Defois. In fine, c'est bien, répétons-le, la mise en lumière du « système » de 
la ville atlantique étudié à partir du milieu négociant rochelais, dont l'organisation était inconnue, qui constitue l'enjeu scientifique de la recherche.

3 L'ouvrage de Brice Martinetti, issu d'une thèse de doctorat soutenue en 2012 à l'université de La Rochelle, s'intéresse plus précisément à la seconde période faste du commerce rochelais après le take off $\mathrm{du} \mathrm{XVII}^{\mathrm{e}}$ siècle brutalement interrompu par la Révocation de 1685, c'est-à-dire le formidable essor du XVIII ${ }^{e}$ siècle. C'est alors que le commerce en droiture avec les Antilles, les échanges franco-canadiens, puis le trafic négrier suscitent une dynamique exceptionnelle dont profite le groupe de négociants, devenu élite sociale. Le propos de l'autreur est d'en définir les caractéristiques essentielles en examinant, selon une "démarche processuelle ( (p. 22), les trajectoires de vie et en comparant sans cesse les résultats obtenus grâce à la méthode prosopographique avec les traits des milieux négociants des autres villes portuaires. L'auteur s'est appuyé sur le dépouillement systématique (qui force l'admiration) de l'intégralité des minutes des quatre-vingt huit notaires rochelais de 1715 à 1815 (plus de 8000 actes), mais il n'a ignoré ni les papiers de familles ni les fonds des institutions rochelaises comme la Chambre de commerce, fondée en 1719, l'amirauté, les cours et juridictions communales. Regrettons au passage que les archives municipales ne soient que partiellement exploitées, mais il est vrai que les registres paroissiaux et les délibérations du corps municipal pouvaient apparaitre d'un intérêt moindre, s'agissant d'analyser un groupe majoritairement protestant et peu soucieux du pouvoir politique. L'auteur s'est donné pour tâche essentielle de décrire avec un soin méticuleux un groupe accédant à la suprématie sociale : comment la première élite de la province d'Aunis s'est-elle formée et comment a-t-elle tenu le haut du pavé un siècle durant ?

Trois parties structurent alors l'ouvrage et définissent parfaitement les contours du groupe : «Entre héritiers et nouveaux venus : formation et structuration d'une élite économique pétrie de diversités ", "Sociabilités et notoriétés urbaines : les négociants dans la vie publique rochelaise", "À la confluence des affaires et du mimétisme nobiliaire naît un nouveau genre de vie ». Au terme de chaque chapitre et de chaque partie, des bilans partiels synthétiques et parfaitement clairs marquent les étapes de la démonstration, sans cependant éviter des répétitions qui distraient l'attention du lecteur.

5 La première partie, la plus attendue dans une recherche d'histoire sociale, montre que le monde du négoce se détache progressivement de la marchandise pour former une «aristocratie du commerce» (P. 33), éloignée du peuple, polyvalente, trafiquant à l'échelle internationale, active aussi bien dans la banque que dans l'assurance, l'armement ou la commission. L'adoption du terme de "négociant " vers 1730 présentes à toutes les couches sociales le prestige de la profession et son honorabilité. $\mathrm{Au}$ total, l'auteur recense sept cent trente-huit négociants résidant à La Rochelle entre 1710 et 1793 . Si leurs fortunes présentent des niveaux très hétérogènes et s'affaissent au cours du siècle en raison de faillites de grande ampleur, elles n'en placent pas moins les négociants au sommet de la hiérarchie sociale rochelaise. L'auteur porte au jour ensuite de manière fort convaincante les modalités de renouvellement du groupe négociant. Ce renouvellement est d'abord le fruit d'une reproduction socioprofessionnelle pure et simple : la continuité de l'activité négociante de père en fils, l'union des fils avec des filles de négociants (cela se produit dans les deux tiers des unions), la transmission rigoureuse des compétences par l'apprentissage au comptoir et la création de sociétés commerciales familiales, au besoin gérées par les veuves, en 
constituent autant de moyens. Pour autant, de nouveaux venus savent trouver leur place, issus principalement de l'élite marchande locale, voire de la noblesse et de la bourgeoisie à talent du port d'Aunis; d'autres immigrants viennent de Saintonge, de Guyenne et de Gascogne, et même, pour 10\% de l'effectif global, des pays protestants de l'Europe du Nord-ouest. Par ailleurs, le processus de reproduction endogène est loin d'être parfait malgré une forte homogamie des alliances; le partage égalitaire de l'héritage comme la recherche d'une intégration dans le second ordre favorisent la sortie du milieu. En définitive, «le tropisme négociant compense le tropisme nobiliaire » (p. 100).

6 Ces observations ont le mérite de montrer sans ambiguïté la nécessité d'articuler en permanence les facteurs culturels et les processus sociaux, les trafics et les hommes, les circulations marchandes et les mobilités humaines. La Rochelle exerce une forte attraction religieuse, économique et familiale car elle constitue le relais comme le point de connexion entre le cabotage continental et le commerce océanique tourné vers les colonies. La composition de son milieu négociant, composite et varié, mêlant les grandes dynasties locales, unies par les intermariages (les Rasteau, les Carayon), les dynasties étrangères moins intégrées (les Butler, les Weis, les Van Hoogwerf) traduit l'insertion du port dans un vaste système économique global et relationnel.

7 Dans la seconde partie, Brice Martinetti analyse la place des négociants dans la mécanique de la vie publique en montrant comment ils défendent leurs intérêts et relèvent les défis que le siècle leur impose. Repoussés des institutions traditionnelles de la cité portuaire - municipalité, présidial, amirauté et bureau des finances, postes consulaires à l'étranger -, ils parviennent à acquérir de notables positions de pouvoir alors même qu'ils sont en grande majorité protestants, cas unique dans l'histoire des ports du royaume. Ce que l'auteur appelle avec bonheur «une stratégie de contournement » leur permet d'investir l'Hôtel de la Monnaie et surtout la Chambre de commerce dans laquelle ils sont majoritaires dès sa création en accaparant la moitié des postes de directeur et la majorité de ceux de syndics, au grand dam des catholiques. Si l'on ajoute que le député rochelais au Conseil du Commerce est une fois sur deux protestant, l'on comprend que les intérêts du négoce sont très bien défendus auprès de la Couronne.

8 La création de nouveaux lieux de sociabilités constitue la seconde conséquence d'une stratégie sociale de promotion destinée tant à hisser les négociants au niveau des élites en place qu'à se définir comme élite citadine, et non plus comme simple élite économique. Les structures éducatives de la cité et l'Académie royale des Belles-lettres, Sciences et arts ayant fermé leurs portes aux adeptes de la R.P.R., les protestants recherchent des formes d'activités culturelles proprement négociantes. Ils tiennent salons, forment des "sociétés » (6 selon l'auteur), élaborent de concert des projets scientifiques, représentent l'essentiel des effectifs des quatre loges maçonniques existantes ( $35 \%$ des deux cent trente-cinq francs-maçons rochelais). D'une manière qui dit beaucoup sur leur puissance sociale, les négociants sont au cœur de l'affirmation de la communauté protestante. Par le biais de "sociétés» qui organisent le culte domestique, et en faisant renaître de ses cendres un consistoire (nommé Comité), ils participent au renforcement du culte et font vivre l'Église clandestine de La Rochelle. En 1765, fait unique en France, un hôpital protestant est créé, les épouses de négociants gérant l'institution. C'est donc à leur propre initiative que les négociants obtiennent de l'influence; ils en tirent une fierté certaine et une identité collective qui leur donnent 
la force d'affronter les défis du temps. Ils rencontrent pourtant l'échec et le désaveu de l'Histoire. La perte du Canada en 1763 et du commerce des pelleteries marque le départ du continent américain, obligeant le négoce à se concentrer sur la droiture avec SaintDomingue et la traite, soit deux marchés spéculatifs et à hauts risques. Dès lors, l'étiolement de l'activité portuaire se révèle sans remède; la Révolution française, synonyme de dirigisme économique, de chute des assignats, de la perte de SaintDomingue et de l'abolition de la traite (définitive en 1794) scelle le destin du port et de son élite pour un siècle au moins.

9 Les négociants rochelais ont néanmoins créé un nouveau genre de vie pour apporter à tous la preuve tangible de leur réussite sociale. La dernière partie de l'ouvrage, des plus classiques mais foisonnante, s'attache à rendre visible une domination sociale «à travers le prisme de la matérialité du milieu négociant » (P. 257) à la suite des études de Michel Figeac et Philippe Gardey sur la vie matérielle des élites bordelaises. Comme il existe un "espace de la noblesse» (M. de Saint-Martin), un espace social propre aux négociants voit le jour. Il se déploie à trois échelles différentes. À Saint-Domingue, une vingtaine «d'habitations » peuvent être identifiées, parmi lesquelles l'indigoterie de Belin Desmarais, qui fait l'objet d'une étude de cas éclairante. Apparaît ainsi une petite société solidement structurée autour d'un réseau d'agents qui relient la plantation à la cité d'Aunis. À l'échelle de l'Aunis, justement, les négociants rochelais, profondément citadins, investissent dans des propriétés rurales (quatre-vingt quinze villégiatures, maisons de maîtres et châteaux identifiés) concentrées dans un rayon de quelques kilomètres autour du port et destinées au repos pendant la période estivale; des exploitations rurales d'une cinquantaine d'hectares - les «cabanes»-, des marais salants et des vignes constituent une forme d'investissement diversifié et surtout plus productif. Ces acquisitions ont certes un but spéculatif, mais leur fonction essentielle est de servir de placements sûrs aux profits commerciaux en assurant au propriétaire une réserve potentielle de liquidités et des revenus réguliers quand le commerce languit. À La Rochelle même, le souci de « démarcation sociale » (p. 260) des négociants les conduit à se concentrer dans un quartier privilégié au sud-ouest de la ville, loti d'hôtels particuliers qui affirment dans la pierre et sur le territoire la réalité d'une ascension sociale.

Dans l'intimité de ces espaces sociaux, à la ville comme à la campagne, les négociants inventent un art de vivre au quotidien partagé par tous et fondé sur « la dynamique de la consommation ostentatoire » (p. 287). Au cœur de la vie de famille et de l'activité professionnelle se trouvent les chambres à coucher, luxueusement décorées, les lieux d'hygiène et le comptoir, sobre, rempli de livres et voué au labeur. Les autres pièces sont réservées au paraître et à la mise en scène du foyer. Au travers de ce puissant désir d'imiter l'homme de cour naît une culture matérielle originale mais éphémère.

11 Dans cet ouvrage solide de 447 pages, illustré de deux dossiers de photographies qui mettent en relation le présent et la splendeur passée du port rochelais, en outre riche de tableaux, graphiques et cartes soignés et très lisibles, le sujet est parfaitement cerné et mis en lumière. Certes, la volonté d'envisager le monde du négoce rochelais dans toutes ces dimensions mène à des analyses souvent descriptives et énumératives sur les bibliothèques ou les habitations des îles, au détriment de la mise en perspective et de l'explication. Par ailleurs, la thèse de la crise du commerce maritime à partir de 1789 et de ses effets sociaux aurait pu être davantage discutée afin de décrire moins sommairement les stratégies mises en œuvre (souvent illégales) pour faire face aux 
difficultés de la conjoncture, mais également les opportunités sociales qu'offre la disparition de l'élite négociante (peut-on la nommer "impériale»?). Cet ouvrage important et d'une lecture toujours passionnante pour qui s'intéresse aux élites sociales fournit toutefois des apports majeurs. En insistant sur la puissante originalité de l'élite commerçante rochelaise reconstituée dans une conclusion très ferme, il éclaire tout un pan de l'évolution des négoces maritimes français. Il souligne aussi indirectement le poids décisif des révoltes coloniales dans l'histoire de la Révolution et la nécessité de dépasser le cadre national pour pouvoir en saisir toutes les dimensions. L'ouvrage démontre également toute l'importance des monographies dans la construction du savoir historique: aussi nécessaire qu'elle soit, l'élaboration d'un «modèle » du milieu négociant doit toujours se confronter aux leçons des archives, à la fraîcheur de l'inconnu et à la vie concrète des individus dans l'infinie diversité de la France moderne. 